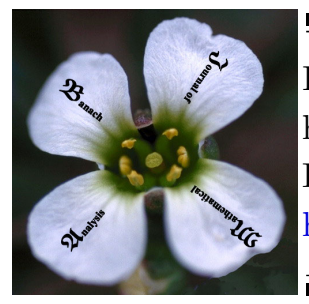

Banach J. Math. Anal. 9 (2015), no. 1, 42-53

http://doi.org/10.15352/bjma/09-1-4

ISSN: $1735-8787$ (electronic)

http://projecteuclid.org/bjma

\title{
LOCALLY 2-UNIFORM CONVEXITY AND BALL-COVERING PROPERTY IN BANACH SPACE
}

\author{
SHAOQIANG SHANG ${ }^{1 *}$ AND YUNAN CUI ${ }^{2}$
}

Communicated by D. E. Alspach

\begin{abstract}
In this paper, we prove that if $X$ is a separable space and $X^{*}$ is a locally 2 -uniform convex space, then for any $0<\varepsilon<1$, there exist sequences $\left\{x_{n, 1}^{*}\right\}_{n=1}^{\infty}$ and $\left\{x_{n, 2}^{*}\right\}_{n=1}^{\infty}$ of strongly extreme points such that

$$
\bigcup_{n=1}^{\infty}\left\{B\left(x_{n, 1}^{*}, 1-\frac{1}{8} \varepsilon\right) \cup B\left(x_{n, 2}^{*}, 1-\frac{1}{8} \varepsilon\right) \cup B\left(\frac{x_{n, 1}^{*}+x_{n, 2}^{*}}{2}, \varepsilon\right)\right\}
$$

is a ball-covering of $X^{*}$. Moreover, we also prove that if (1) $X$ is a separable space; (2) $X$ is a locally 2-uniform convex space; (3) $X$ is a uniformly nonsquare space, then there exists a sequence $\left\{x_{n}\right\}_{n=1}^{\infty}$ of strongly extreme points such that $\bigcup_{n=1}^{\infty} B\left(x_{n}, r_{n}\right)$ is a ball-covering of $X$.
\end{abstract}

\section{INTRODUCTION AND PRELIMINARIES}

Let $(X,\|\cdot\|)$ be a real Banach space. $S(X)$ and $B(X)$ denote the unit sphere and unit ball, respectively. By $X^{*}$ denote the dual space of $X . B(x, r)$ denote the open ball centered at $x$ and of radius $r>0 . \bar{C}$ denote closed hull of $C$. $\operatorname{dist}(x, C)$ denote the distance of $x$ and $C$. Let $N, R$ and $R^{+}$denote the sets of natural number, reals and nonnegative reals, respectively.

The study of geometric and topological properties of unit balls of Banach spaces plays a central rule in the geometry of Banach spaces. Almost all properties

Date: Received: Oct. 28, 2013; Revised: Feb. 10, 2014; Accepted: Mar. 1, 2014.

${ }^{*}$ Corresponding author.

2010 Mathematics Subject Classification. Primary 46B20; Secondary 46B03.

Key words and phrases. locally 2-uniform convex space, ball-covering property, strongly extreme point, 2-strictly convex space. 
of Banach spaces, such as convexity, smoothness, reflexivity and the RadonNikodym property, can be viewed as properties of the unit ball. We should mention here that there are many topics studying behavior of ball collections. For example, the Mazur intersection property, the packing sphere problem of unit balls, the measure of non-compactness with respect to topological degree, and the ball topology have also brought great attention of many mathematicians.

Starting with a different viewpoint, a notion of ball-covering property is introduced by Cheng in [3].

Definition 1.1. A Banach space is said to have the ball-covering property if its unit sphere can be contained in the union of countably many balls off the origin.

In [2], Cheng proved that if $X$ is a locally uniformly convex space and $B\left(X^{*}\right)$ is $w^{*}$-separable, then $X$ has the ball-covering property. In [4], Cheng and Liu proved that by constructing the equivalent norms on $l^{\infty}$, there exists a Banach space $\left(l^{\infty},\|\cdot\|^{0}\right)$ such that $\left(l^{\infty},\|\cdot\|^{0}\right)$ has not the ball-covering property. In [7], it was established that for every $\varepsilon>0$ every Banach space with a $w^{*}$-separable dual has an $1+\varepsilon$-equivalent norm with the ball-covering property.

Let us recall some geometrical notions which will be used in the further part of the paper.

Definition 1.2. A Banach space $X$ is said to be uniformly nonsquare if for any $x, y \in S(X)$, there exists $\delta>0$ such that $\min \{\|x+y\|,\|x-y\|\}<2-\delta$.

Definition 1.3. A point $x \in S(X)$ is said to be a strongly extreme point if for any $\left\{x_{n}\right\}_{n=1}^{\infty} \subset X,\left\{y_{n}\right\}_{n=1}^{\infty} \subset X$ with $\left\|x_{n}\right\| \rightarrow 1,\left\|y_{n}\right\| \rightarrow 1$ and $2 x=x_{n}+y_{n}$, there holds $\left\|x_{n}-y_{n}\right\| \rightarrow 0$ as $n \rightarrow \infty$. The set of all strongly extreme points of $B(X)$ is denoted by $\operatorname{SExt} B(X)$.

F. Sullivan defined the locally $k$-uniform convex spaces in [14]. I. Singer defined the $k$-strictly convex spaces in [13].

Definition 1.4. A Banach space $X$ is said to be locally $k$-uniform convex if for any $x \in S(X), \varepsilon>0$, there exists $\delta_{x, \varepsilon}>0$ such that $x_{1}, \cdots, x_{k} \in S(X)$ and $\left\|x+x_{1}+\cdots+x_{k}\right\| \geq k+1-\delta_{x, \varepsilon}$ implies

$$
\Delta\left(x, x_{1}, \cdots, x_{k}\right)=\sup _{x_{i}^{*} \in S\left(X^{*}\right)}\left|\begin{array}{cccc}
1 & 1 & \cdots & 1 \\
x_{1}^{*}(x) & x_{1}^{*}\left(x_{1}\right) & \cdots & x_{1}^{*}\left(x_{k}\right) \\
\cdots & \cdots & \cdots & \cdots \\
x_{k}^{*}(x) & x_{k}^{*}\left(x_{1}\right) & \cdots & x_{k}^{*}\left(x_{k}\right)
\end{array}\right|<\varepsilon .
$$

Definition 1.5. A Banach space $X$ is said to be $k$-strictly convex if for any $k+1$ elements $x_{1}, x_{2}, \cdots, x_{k+1} \in S(X)$, if $\left\|x_{1}+x_{2}+\cdots+x_{k+1}\right\|=k+1$, then $x_{1}, x_{2}, \cdots, x_{k+1}$ are linearly dependent.

It is well known that if $X$ is locally $k$-uniform convex, then $X$ is $k$-strictly convex. Clearly, every separable space has ball-covering property, but the converse version is not true. Moreover, there exists a separable space $X$ such that $X^{*}$ is not separable. It is very natural to ask in which separable Banach spaces $X, X^{*}$ has the ball-covering property. In this paper, we prove that if $X$ is a separable 
space and $X^{*}$ is a locally 2 -uniform convex space, then for any $0<\varepsilon<1$, there exist sequences $\left\{x_{n, 1}^{*}\right\}_{n=1}^{\infty}$ and $\left\{x_{n, 2}^{*}\right\}_{n=1}^{\infty}$ of strongly extreme points such that

$$
S\left(X^{*}\right) \subset \bigcup_{n=1}^{\infty}\left\{B\left(x_{n, 1}^{*}, 1-\frac{1}{8} \varepsilon\right) \cup B\left(x_{n, 2}^{*}, 1-\frac{1}{8} \varepsilon\right) \cup B\left(\frac{x_{n, 1}^{*}+x_{n, 2}^{*}}{2}, \varepsilon\right)\right\} .
$$

Moreover, we also prove that if (1) $X$ is a separable space; (2) $X$ is a locally 2-uniform convex space; (3) $X$ is a uniformly nonsquare space, then there exists a sequence $\left\{x_{n}\right\}_{n=1}^{\infty}$ of strongly extreme points such that $\cup_{n=1}^{\infty} B\left(x_{n}, r_{n}\right)$ is a ballcovering of $X$. The topic of this paper is related to the topic of [1]-[12].

\section{MAin RESUlts}

Theorem 2.1. Suppose that $X$ is a separable space and $X^{*}$ is a locally 2-uniform convex space. Then for any $0<\varepsilon<1$, there exist sequences $\left\{x_{n, 1}^{*}\right\}_{n=1}^{\infty}$ and $\left\{x_{n, 2}^{*}\right\}_{n=1}^{\infty}$ of strongly extreme points such that

$$
S\left(X^{*}\right) \subset \bigcup_{n=1}^{\infty}\left\{B\left(x_{n, 1}^{*}, 1-\frac{1}{8} \varepsilon\right) \cup B\left(x_{n, 2}^{*}, 1-\frac{1}{8} \varepsilon\right) \cup B\left(\frac{x_{n, 1}^{*}+x_{n, 2}^{*}}{2}, \varepsilon\right)\right\} .
$$

Proof. (a) First we will prove that for any $x \in S(X)$, if $x_{n}^{*}(x) \rightarrow 1$, then $\left\{x_{n}^{*}\right\}_{n=1}^{\infty}$ has a Cauchy subsequence. Suppose that $\left\{x_{n}^{*}\right\}_{n=1}^{\infty}$ has not Cauchy subsequence. Then $\left\{x_{n}^{*}\right\}_{n=1}^{\infty}$ is not relatively compact. Hence there exists $\varepsilon_{0}>0$ such that $\left\{x_{n}^{*}\right\}_{n=1}^{\infty}$ has not finite $\varepsilon_{0}$-net. Pick $x^{*} \in A(x)=\left\{x^{*} \in S\left(X^{*}\right): x^{*}(x)=\|x\|=\right.$ $1\}$. We claim that there exist $x_{1,1}^{*} \in\left\{x_{n}^{*}\right\}_{n=1}^{\infty}$ and $x_{1,2}^{*} \in\left\{x_{n}^{*}\right\}_{n=1}^{\infty}$ such that

$$
\operatorname{dist}\left(x_{1,2}^{*}, \operatorname{span}\left\{x^{*}, x_{1,1}^{*}\right\}\right) \geq \frac{\varepsilon_{0}}{4} \text {. }
$$

Otherwise, for any $x_{n}^{*}$, we have $\operatorname{dist}\left(x_{n}^{*}, \operatorname{span}\left\{x^{*}, x_{1}^{*}\right)\right\}<\varepsilon_{0} / 4$ whenever $n \geq 2$. Then there exists $y_{n}^{*} \in \operatorname{span}\left\{x^{*}, x_{1}^{*}\right\}$ such that

$$
\left\|x_{n}^{*}-y_{n}^{*}\right\|=\operatorname{dist}\left(x_{n}^{*}, \operatorname{span}\left\{x^{*}, x_{1}^{*}\right\}\right)<\frac{\varepsilon_{0}}{4} .
$$

It is easy to see that $\left\{y_{n}^{*}\right\}_{n=1}^{\infty}$ is a bounded sequence. Then $\left\{y_{n}^{*}\right\}_{n=1}^{\infty}$ is relatively compact. This implies that $\left\{y_{n}^{*}\right\}_{n=1}^{\infty}$ has a finite $\varepsilon_{0} / 4$-net. By $\left\|x_{n}^{*}-y_{n}^{*}\right\| \leq$ $\varepsilon_{0} / 4$, we obtain that $\left\{x_{n}^{*}\right\}_{n=1}^{\infty}$ has a finite $\varepsilon_{0}$-net, a contradiction. Hence there exist $x_{2,1}^{*} \in\left\{x_{n}^{*}\right\}_{n=1}^{\infty} \backslash\left\{x_{1,1}^{*}, x_{1,2}^{*}\right\}$ and $x_{2,2}^{*} \in\left\{x_{n}^{*}\right\}_{n=1}^{\infty} \backslash\left\{x_{1,1}^{*}, x_{1,2}^{*}\right\}$ such that $\operatorname{dist}\left(x_{2,2}^{*}, \operatorname{span}\left\{x^{*}, x_{2,1}^{*}\right\}\right) \geq \varepsilon_{0} / 4$.

Generally, there exist $x_{n, 1}^{*} \in\left\{x_{n}^{*}\right\}_{n=1}^{\infty} \backslash\left\{x_{1,1}^{*}, x_{1,2}^{*}, x_{2,1}^{*}, x_{2,2}^{*}, \cdots, x_{n-1,1}^{*}, x_{n-1,2}^{*}\right\}$ and $x_{n, 2}^{*} \in\left\{x_{n}^{*}\right\}_{n=1}^{\infty} \backslash\left\{x_{1,1}^{*}, x_{1,2}^{*}, x_{2,1}^{*}, x_{2,2}^{*}, \cdots, x_{n-1,1}^{*}, x_{n-1,2}^{*}\right\}$ such that

$$
\operatorname{dist}\left(x_{n, 2}^{*}, \operatorname{span}\left\{x^{*}, x_{n, 1}^{*}\right\}\right) \geq \frac{\varepsilon_{0}}{4} \text {. }
$$

Hence we define two sequences $\left\{x_{n, 1}^{*}\right\}_{n=1}^{\infty}$ and $\left\{x_{n, 2}^{*}\right\}_{n=1}^{\infty}$. Moreover, we may assume that

$$
3 \geq\left\|x^{*}+x_{n, 1}^{*}+x_{n, 2}^{*}\right\| \geq x^{*}(x)+x_{n, 1}^{*}(x)+x_{n, 2}^{*}(x) \rightarrow 3 \text { as } n \rightarrow \infty .
$$

This implies that $\left\|x^{*}+x_{n, 1}^{*}+x_{n, 2}^{*}\right\| \rightarrow 3$ as $n \rightarrow \infty$. Since $\left\{x_{n}^{*}\right\}_{n=1}^{\infty}$ has not Cauchy subsequence, there exists $\eta>0$ such that $\eta=\inf \left\{\left\|x_{n}^{*}-x^{*}\right\|: n \in N\right\}$. 
By Hahn-Banach theorem, there exist $x_{n, 1}^{* *} \in S\left(X^{* *}\right)$ and $x_{n, 2}^{* *} \in S\left(X^{* *}\right)$ such that

$$
x_{n, 1}^{* *}\left(x^{*}\right)=0, \quad x_{n, 1}^{* *}\left(x_{n, 1}^{*}\right) \geq \eta
$$

and

$$
x_{n, 2}^{* *}\left(x^{*}\right)=0, \quad x_{n, 2}^{* *}\left(x_{n, 1}^{*}\right)=0, \quad x_{n, 2}^{* *}\left(x_{n, 2}^{*}\right) \geq \frac{\varepsilon_{0}}{4} .
$$

Therefore, by (2.1) and (2.2), we have

$$
\Delta\left(x^{*}, x_{n, 2}^{*}, x_{n, 3}^{*}\right) \geq\left|\begin{array}{ccc}
1 & 1 & 1 \\
x_{n, 1}^{* *}\left(x^{*}\right) & x_{n, 1}^{* *}\left(x_{n, 1}^{*}\right) & x_{n, 1}^{* *}\left(x_{n, 2}^{*}\right) \\
x_{n, 2}^{* *}\left(x^{*}\right) & x_{n, 2}^{* *}\left(x_{n, 1}^{*}\right) & x_{n, 2}^{* *}\left(x_{n, 2}^{*}\right)
\end{array}\right| \geq \frac{\varepsilon_{0}}{4} \eta,
$$

contradicting the locally 2-uniform convexity of $X^{*}$.

(b) Let $\left\{z_{k}^{*}\right\}_{k=1}^{\infty} \subset A(x)$. Then $z_{k}^{*}(x)=1$. By the proof of (a), we obtain that $\left\{z_{k}^{*}\right\}_{k=1}^{\infty}$ has a Cauchy subsequence. Moreover, it is easy to see that $A(x)$ is a closed set. Hence $A(x)$ is compact.

We will prove that for any $x \in S(X)$, the set $A(x)$ is a line segment or a singleton. In fact, for any $x_{1}^{*} \in A(x), x_{2}^{*} \in A(x)$ and $x_{3}^{*} \in A(x)$, we have

$$
\left\|x_{1}^{*}+x_{2}^{*}+x_{3}^{*}\right\| \geq\left(x_{1}^{*}+x_{2}^{*}+x_{3}^{*}\right)(x)=3=\left\|x_{1}^{*}\right\|+\left\|x_{2}^{*}\right\|+\left\|x_{3}^{*}\right\| .
$$

Hence $\left\|x_{1}^{*}+x_{2}^{*}+x_{3}^{*}\right\|=\left\|x_{1}^{*}\right\|+\left\|x_{2}^{*}\right\|+\left\|x_{3}^{*}\right\|$. Since $X^{*}$ is locally 2-uniform convex, $X^{*}$ is 2 -strictly convex. Hence we may assume that $x_{3}^{*}=t_{1} x_{1}^{*}+t_{2} x_{2}^{*}$. Thus

$$
1=x_{3}^{*}(x)=\left(t_{1} x_{1}^{*}+t_{2} x_{2}^{*}\right)(x)=t_{1} x_{1}^{*}(x)+t_{2} x_{2}^{*}(x)=t_{1}+t_{2} .
$$

Since $A(x)$ is compact, there exist $y_{1}^{*} \in A(x)$ and $y_{2}^{*} \in A(x)$ such that

$$
d(x)=\sup \left\{\left\|x^{*}-y^{*}\right\|: x^{*} \in A(x), y^{*} \in A(x)\right\}=\left\|y_{1}^{*}-y_{2}^{*}\right\| .
$$

For clarity, we will divide the proof into two cases.

Case I. Let $y_{1}^{*}=y_{2}^{*}$. Then $A(x)$ is a single-point set.

Case II. Let $y_{1}^{*} \neq y_{2}^{*}$. Then, for any $y^{*} \in A(x)$, if $y_{1}^{*}=t y^{*}+(1-t) y_{2}^{*}$, then $t \neq 0$. Otherwise, we have $y_{1}^{*}=y_{2}^{*}$. Hence, for any $y^{*} \in A(x)$, we have $y^{*}=\alpha y_{1}^{*}+(1-\alpha) y_{2}^{*}$. Suppose that $\alpha<0$. Then

$$
y^{*}=\alpha y_{1}^{*}+(1-\alpha) y_{2}^{*} \Rightarrow y_{2}^{*}=\frac{1}{1-\alpha} y^{*}+\frac{-\alpha}{1-\alpha} y_{1}^{*}
$$

Hence

$$
\left\|y_{1}^{*}-y_{2}^{*}\right\|=\left\|y_{1}^{*}-\frac{1}{1-\alpha} y^{*}-\frac{-\alpha}{1-\alpha} y_{1}^{*}\right\|=\frac{-\alpha}{1-\alpha}\left\|y_{1}^{*}-y^{*}\right\|<\left\|y_{1}^{*}-y^{*}\right\|,
$$

a contradiction. Similarly, we have $1-\alpha \geq 0$. Thus $\alpha \in[0,1]$. This implies that for any $x \in S(X)$, there exist $x_{1, x}^{*} \in A(x)$ and $x_{2, x}^{*} \in A(x)$ such that

$$
A(x)=\left[x_{1, x}^{*}, x_{2, x}^{*}\right]=\left\{z^{*}: z^{*}=\lambda x_{1, x}^{*}+(1-\lambda) x_{2, x}^{*}, \lambda \in[0,1]\right\} .
$$

(c) We will prove that for any $n \in N, x_{n, 1}^{*}$ and $x_{n, 2}^{*}$ are strongly extreme points. Let $2 x_{n, 1}^{*}=y_{k}^{*}+z_{k}^{*}, \lim _{k \rightarrow \infty}\left\|y_{k}^{*}\right\|=1$ and $\lim _{k \rightarrow \infty}\left\|z_{k}^{*}\right\|=1$. Since

$$
2=2 x_{n, 1}^{*}\left(x_{n}\right)=y_{k}^{*}\left(x_{n}\right)+z_{k}^{*}\left(x_{n}\right), \lim _{k \rightarrow \infty}\left\|y_{k}^{*}\right\|=1 \text { and } \lim _{k \rightarrow \infty}\left\|z_{k}^{*}\right\|=1 \text {, }
$$


we have

$$
2=\limsup _{k \rightarrow \infty}\left(y_{k}^{*}\left(x_{n}\right)+z_{k}^{*}\left(x_{n}\right)\right) \leq \limsup _{k \rightarrow \infty} y_{k}^{*}\left(x_{n}\right)+\limsup _{k \rightarrow \infty} z_{k}^{*}\left(x_{n}\right) \leq 2 .
$$

Therefore, by (2.3) and (2.4), we have $\lim \sup y_{k}^{*}\left(x_{n}\right)=1$. Hence there exists a subsequence $\left\{k_{i}\right\}$ of $\{k\}$ such that $\lim _{i \rightarrow \infty} y_{k_{i}}^{* \rightarrow \infty}\left(x_{n}\right)=1$. By the proof of $(\mathrm{a})$, there exists a subsequence $\left\{k_{l}\right\}$ of $\left\{k_{i}\right\}$ such that $\left\{y_{k_{l}}^{*}\right\}_{l=1}^{\infty}$ is a Cauchy sequence. Let $y^{*}=\lim _{l \rightarrow \infty} y_{k_{l}}^{*}$. By $2 x_{n, 1}^{*}=y_{k}^{*}+z_{k}^{*}$, we obtain that $\left\{z_{k_{l}}^{*}\right\}_{l=1}^{\infty}$ is a Cauchy sequence. Let $z^{*}=\lim _{l \rightarrow \infty} z_{k_{l}}^{*}$. Then $\left\|y^{*}\right\|=\left\|z^{*}\right\|=1$ and $2 x_{n, 1}^{*}=y^{*}+z^{*}$. Since

$$
2=2 x_{n, 1}^{*}\left(x_{n}\right)=y^{*}\left(x_{n}\right)+z^{*}\left(x_{n}\right) \leq 1+1 \Rightarrow y^{*}\left(x_{n}\right)=z^{*}\left(x_{n}\right)=1,
$$

we have $y^{*} \in A\left(x_{n}\right)$ and $z^{*} \in A\left(x_{n}\right)$. By $A\left(x_{n}\right)=\left[x_{n, 1}^{*}, x_{n, 2}^{*}\right]$, we have $y^{*}=z^{*}=$ $x_{n, 1}^{*}$. Then $\lim _{k \rightarrow \infty} y_{k}^{*}=x_{n, 1}^{*}$. Otherwise, there exist $\delta>0$ and a subsequence $\left\{n_{j}\right\}$ of $\{n\}$ such that $\left\|y_{k_{j}}^{*}-x_{n, 1}^{*}\right\| \geq \delta$. By the previous proof, there exists a subsequence $\left\{n_{h}\right\}$ of $\left\{n_{l}\right\}$ such that $\lim _{h \rightarrow \infty} y_{k_{h}}^{*}=x_{n, 1}^{*}$, a contradiction. By $2 x_{n, 1}^{*}=y_{k}^{*}+z_{k}^{*}$, we have $\lim _{k \rightarrow \infty} z_{k}^{*}=x_{n, 1}^{*}$. Hence $x_{n, 1}^{*}$ is a strongly extreme point. Similarly, we obtain that $x_{n, 2}^{*}$ is a strongly extreme point.

(d) For any $0<\varepsilon<1$ and $n \in N$, we define open balls

$$
B\left(x_{n, 1}^{*}, 1-\frac{1}{4} \varepsilon\right), B\left(x_{n, 2}^{*}, 1-\frac{1}{4} \varepsilon\right) \text { and } B\left(\frac{x_{n, 1}^{*}+x_{n, 2}^{*}}{2}, \frac{1}{2} \varepsilon\right) .
$$

We claim that if $\limsup \operatorname{dist}\left(A\left(x_{n}\right), y^{*}\right) \leq \varepsilon / 16$, then

$$
y^{*} \in \bigcup_{n=1}^{\infty}\left\{B\left(x_{n, 1}^{*}, 1-\frac{1}{4} \varepsilon\right) \cup B\left(x_{n, 2}^{*}, 1-\frac{1}{4} \varepsilon\right) \cup B\left(\frac{x_{n, 1}^{*}+x_{n, 2}^{*}}{2}, \frac{1}{2} \varepsilon\right)\right\} .
$$

In fact, since $\lim \sup \operatorname{dist}\left(A\left(x_{n}\right), y^{*}\right) \leq \varepsilon / 16$, there exists natural number $n_{0}$ such that $\operatorname{dist}\left(A\left(x_{n_{0}}\right), y^{*}\right) \leq \varepsilon / 12$. Since $A\left(x_{n_{0}}\right)$ is compact, there exists $z_{0}^{*} \in A\left(x_{n_{0}}\right)=$ $\left[x_{n_{0}, 1}^{*}, x_{n_{0}, 2}^{*}\right]$ such that $\operatorname{dist}\left(A\left(x_{n_{0}}\right), y^{*}\right)=\left\|y^{*}-z_{0}^{*}\right\| \leq \varepsilon / 12$. If $\| z_{0}^{*}-\left(x_{n_{0}, 1}^{*}+\right.$ $\left.x_{n_{0}, 2}^{*}\right) / 2 \|<\varepsilon / 4+\varepsilon / 11$, then

$$
\left\|y^{*}-\frac{x_{n_{0}, 1}^{*}+x_{n_{0}, 2}^{*}}{2}\right\| \leq\left\|y^{*}-z_{0}^{*}\right\|+\left\|z_{0}^{*}-\frac{x_{n_{0}, 1}^{*}+x_{n_{0}, 2}^{*}}{2}\right\| \leq \frac{\varepsilon}{12}+\frac{\varepsilon}{4}+\frac{\varepsilon}{11}<\frac{\varepsilon}{2} .
$$

This implies that $y^{*} \in B\left(\left(x_{n_{0}, 1}^{*}+x_{n_{0}, 2}^{*}\right) / 2, \varepsilon / 2\right)$. Since $z_{0}^{*} \in\left[x_{n_{0}, 1}^{*},\left(x_{n_{0}, 1}^{*}+x_{n_{0}, 2}^{*}\right) / 2\right]$ or $z_{0}^{*} \in\left[\left(x_{n_{0}, 1}^{*}+x_{n_{0}, 2}^{*}\right) / 2, x_{n_{0}, 2}^{*},\right]$, we may assume that $z_{0}^{*} \in\left[x_{n_{0}, 1}^{*},\left(x_{n_{0}, 1}^{*}+x_{n_{0}, 2}^{*}\right) / 2\right]$. Since $\left\|x_{n_{0}, 1}^{*}-x_{n_{0}, 2}^{*}\right\| \leq 2$, we have $\left\|x_{n_{0}, 1}^{*}-\left(x_{n_{0}, 1}^{*}+x_{n_{0}, 2}^{*}\right) / 2\right\| \leq 1$. Hence, if $\left\|z_{0}^{*}-\left(x_{n_{0}, 1}^{*}+x_{n_{0}, 2}^{*}\right) / 2\right\| \geq \varepsilon / 4+\varepsilon / 11$, then

$$
\left\|z_{0}^{*}-x_{n_{0}, 1}^{*}\right\|=\left\|x_{n_{0}, 1}^{*}-\frac{x_{n_{0}, 1}^{*}+x_{n_{0}, 2}^{*}}{2}\right\|-\left\|z_{0}^{*}-\frac{x_{n_{0}, 1}^{*}+x_{n_{0}, 2}^{*}}{2}\right\| \leq 1-\frac{\varepsilon}{4}-\frac{\varepsilon}{11} .
$$

This implies that

$$
\left\|y^{*}-x_{n_{0}, 1}^{*}\right\| \leq\left\|y^{*}-z_{0}^{*}\right\|+\left\|z_{0}^{*}-x_{n_{0}, 1}^{*}\right\| \leq \frac{\varepsilon}{12}+1-\frac{\varepsilon}{4}-\frac{\varepsilon}{11}<1-\frac{\varepsilon}{4} .
$$

Hence $y^{*} \in B\left(x_{n_{0}, 1}^{*}, 1-\varepsilon / 4\right)$. 
(e) Let $d(x)=\sup \left\{\left\|x^{*}-y^{*}\right\|: x^{*} \in A(x), y^{*} \in A(x)\right\}$ and $d=\sup \{d(x): x \in$ $S(X)\}$. It is easy to see that there exist $d_{1}, d_{2}, \ldots, d_{m} \in(\varepsilon / 32, d)$ such that

$$
\left(d_{1}-\frac{\varepsilon}{(32)^{2}}, d_{1}+\frac{\varepsilon}{(32)^{2}}\right) \cup, \ldots, \cup\left(d_{m}-\frac{\varepsilon}{(32)^{2}}, d_{m}+\frac{\varepsilon}{(32)^{2}}\right) \supset\left(\frac{\varepsilon}{32}, d\right)
$$

Put

and

$$
\begin{gathered}
H_{i}^{*}=\left\{x^{*}: x^{*} \in A(x), d_{i}-\frac{\varepsilon}{(32)^{2}}<d(x)<d_{i}+\frac{\varepsilon}{(32)^{2}}\right\}, \\
H_{i}=\left\{x \in S(X): d_{i}-\frac{\varepsilon}{(32)^{2}}<d(x)<d_{i}+\frac{\varepsilon}{(32)^{2}}\right\}
\end{gathered}
$$

$$
H=\left\{x \in S(X): d(x) \leq \frac{\varepsilon}{32}\right\}
$$

for any $1 \leq i \leq m$. It is easy to see that $H_{1} \cup \ldots \cup H_{m} \cup H=S(X)$. Next we will prove that for any $y^{*} \in A(x)$, we have

$$
y^{*} \in \bigcup_{n=1}^{\infty}\left\{B\left(x_{n, 1}^{*}, 1-\frac{1}{4} \varepsilon\right) \cup B\left(x_{n, 2}^{*}, 1-\frac{1}{4} \varepsilon\right) \cup B\left(\frac{x_{n, 1}^{*}+x_{n, 2}^{*}}{2}, \frac{1}{2} \varepsilon\right)\right\} .
$$

For clarity, we will divide the proof into two cases.

Case I. Let $x \in H_{i}$, where $i \in\{1,2, \ldots, m\}$. By the proof of (b), we have $A(x)=\left[y_{1, x}^{*}, y_{2, x}^{*}\right]$. We define a open set

$$
U_{A(x)}=\bigcup_{x^{*} \in\left[y_{1, x}^{*}, y_{2, x}^{*}\right]} B\left(x^{*}, \frac{\varepsilon}{(32)^{2}}\right) .
$$

Since $\left\{x_{n}\right\}_{n=1}^{\infty}$ is a dense subset of $S(X)$, there exists a subsequence $\left\{x_{n, i}\right\}_{n=1}^{\infty}$ of $\left\{x_{n}\right\}_{n=1}^{\infty}$ such that $\left\{x_{n, i}\right\}_{n=1}^{\infty}$ is a dense subset of $H_{i}$. We may assume, without loss of generality, that $x_{n, i} \rightarrow x$ as $n \rightarrow \infty$. Then there exists natural number $N_{1}$ such that $A\left(x_{n, i}\right) \subset U_{A(x)}$ whenever $n>N_{1}$. Otherwise, there exists a subsequence $\left\{n_{k}\right\}$ of $\{n\}$ such that $A\left(x_{n_{k}, i}\right) \not \subset U_{A(x)}$. Then there exists $y_{n_{k}, i}^{*} \in A\left(x_{n_{k}, i}\right)$ such that $y_{n_{k}, i}^{*} \notin U_{A(x)}$. Since

$$
\begin{aligned}
\left|y_{n_{k}, i}^{*}(x)-1\right| & =\left|y_{n_{k}, i}^{*}(x)-y_{n_{k}, i}^{*}\left(x_{n_{k}, i}\right)\right| \\
& \leq\left\|y_{n_{k}, i}^{*}\right\|\left\|x_{n_{k}, i}-x\right\| \\
& \leq\left\|x_{n_{k}, i}-x\right\| \rightarrow 0 \text { as } k \rightarrow \infty
\end{aligned}
$$

by the proof of (a), there exists a subsequence $\left\{y_{n_{l}, i}^{*}\right\}_{l=1}^{\infty}$ of $\left\{y_{n_{k}, i}^{*}\right\}_{k=1}^{\infty}$ such that $\left\{y_{n_{l}, i}^{*}\right\}_{l=1}^{\infty}$ converges to a point of $A(x)$. Which contradict $y_{n_{k}, i}^{*} \notin U_{A(x)}$. We claim that $\lim \sup \operatorname{dist}\left(A\left(x_{n, i}\right), y_{1, x}^{*}\right) \leq \varepsilon / 16$. Otherwise, there exists a subsequence $\left\{n_{k}\right\}$ of $\{n\}$ such that $\lim _{k \rightarrow \infty} \operatorname{dist}\left(A\left(x_{n_{k}, i}\right), y_{1, x}^{*}\right)>\varepsilon / 16$. Hence we may assume that

$$
\left\|y_{1, x}^{*}-y_{1, x}^{*}\left(n_{1}\right)\right\| \geq \frac{\varepsilon}{16}, \quad\left\|y_{1, x}^{*}-y_{2, x}^{*}\left(n_{1}\right)\right\| \geq \frac{\varepsilon}{16} \quad \text { and } \quad n_{1}>N_{1} .
$$

Then $A\left(x_{n_{1}, i}\right)=\left[y_{1, x}^{*}\left(n_{1}\right), y_{2, x}^{*}\left(n_{1}\right)\right] \subset U_{A(x)}$. According to the definition of $U_{A(x)}$, there exist $z_{1, x}^{*} \in\left[y_{1, x}^{*}, y_{2, x}^{*}\right]$ and $z_{2, x}^{*} \in\left[y_{1, x}^{*}, y_{2, x}^{*}\right]$ such that

$$
\left\|z_{1, x}^{*}-y_{1, x}^{*}\left(n_{1}\right)\right\|<\frac{\varepsilon}{(32)^{2}} \text { and }\left\|z_{2, x}^{*}-y_{2, x}^{*}\left(n_{1}\right)\right\|<\frac{\varepsilon}{(32)^{2}} \text {. }
$$


Therefore, by (2.5) and (2.6), we have

$$
\left\|z_{1, x}^{*}-y_{1, x}^{*}\right\| \geq\left\|y_{1, x}^{*}\left(n_{1}\right)-y_{1, x}^{*}\right\|-\left\|z_{1, x}^{*}-y_{1, x}^{*}\left(n_{1}\right)\right\| \geq \frac{\varepsilon}{16}-\frac{\varepsilon}{(32)^{2}}
$$

and

$$
\left\|z_{2, x}^{*}-y_{1, x}^{*}\right\| \geq\left\|y_{2, x}^{*}\left(n_{1}\right)-y_{1, x}^{*}\right\|-\left\|z_{2, x}^{*}-y_{2, x}^{*}\left(n_{1}\right)\right\| \geq \frac{\varepsilon}{16}-\frac{\varepsilon}{(32)^{2}} .
$$

By $z_{1, x}^{*} \in\left[y_{1, x}^{*}, y_{2, x}^{*}\right]$ and $z_{2, x}^{*} \in\left[y_{1, x}^{*}, y_{2, x}^{*}\right]$, we may assume, without loss of generality, that $\left\|z_{1, x}^{*}-z_{2, x}^{*}\right\|=\left\|z_{2, x}^{*}-y_{1, x}^{*}\right\|-\left\|y_{1, x}^{*}-z_{1, x}^{*}\right\|$. Hence

$$
\left\|z_{1, x}^{*}-z_{2, x}^{*}\right\|=\left\|z_{2, x}^{*}-y_{1, x}^{*}\right\|-\left\|y_{1, x}^{*}-z_{1, x}^{*}\right\| \leq d_{i}+\frac{\varepsilon}{(32)^{2}}-\left(\frac{\varepsilon}{16}-\frac{\varepsilon}{(32)^{2}}\right) .
$$

Therefore, by (2.6) and (2.7), we have

$$
\begin{aligned}
\left\|y_{1, x}^{*}\left(n_{1}\right)-y_{2, x}^{*}\left(n_{1}\right)\right\| & \leq\left\|y_{1, x}^{*}\left(n_{1}\right)-z_{1, x}^{*}\right\|+\left\|z_{1, x}^{*}-z_{2, x}^{*}\right\|+\left\|z_{2, x}^{*}-y_{2, x}^{*}\left(n_{1}\right)\right\| \\
& \leq \frac{\varepsilon}{(32)^{2}}+d_{i}+\frac{\varepsilon}{(32)^{2}}-\left(\frac{\varepsilon}{16}-\frac{\varepsilon}{(32)^{2}}\right)+\frac{\varepsilon}{(32)^{2}} \\
& <d_{i}-\frac{\varepsilon}{32} .
\end{aligned}
$$

By $x \in H_{i}$ and $H_{i}^{*}=\left\{x^{*}: x^{*} \in A(x), d_{i}-\varepsilon /(32)^{2}<d(x)<d_{i}+\varepsilon /(32)^{2}\right\}$, we have $\left\|y_{1, x}^{*}\left(n_{1}\right)-y_{2, x}^{*}\left(n_{1}\right)\right\|>d_{i}-\varepsilon /(32)^{2}$, a contradiction. Similarly, we have $\limsup \operatorname{dist}\left(A\left(x_{n, i}\right), y_{2, x}^{*}\right) \leq \varepsilon / 16$. Since $A\left(x_{n, i}\right)$ is compact, by

$$
\limsup _{n \rightarrow \infty} \operatorname{dist}\left(A\left(x_{n, i}\right), y_{1, x}^{*}\right) \leq \frac{\varepsilon}{16} \text { and } \limsup _{n \rightarrow \infty} \operatorname{dist}\left(A\left(x_{n, i}\right), y_{2, x}^{*}\right) \leq \frac{\varepsilon}{16},
$$

there exist $y_{n, 1}^{*} \in A\left(x_{n, i}\right)$ and $y_{n, 2}^{*} \in A\left(x_{n, i}\right)$ such that

$$
\limsup _{n \rightarrow \infty}\left\|y_{n, 1}^{*}-y_{1, x}^{*}\right\| \leq \frac{\varepsilon}{16} \text { and } \limsup _{n \rightarrow \infty}\left\|y_{n, 2}^{*}-y_{2, x}^{*}\right\| \leq \frac{\varepsilon}{16} \text {. }
$$

Moreover, for any $y^{*} \in A(x)$, there exists $\alpha \in[0,1]$ such that

$$
y^{*}=\alpha y_{1, x}^{*}+(1-\alpha) y_{2, x}^{*} .
$$

Therefore, by (2.8) and (2.9), we have

$$
\begin{aligned}
& \limsup _{n \rightarrow \infty}\left\|\alpha y_{n, 1}^{*}+(1-\alpha) y_{n, 2}^{*}-y^{*}\right\| \\
= & \limsup _{n \rightarrow \infty}\left\|\alpha y_{n, 1}^{*}+(1-\alpha) y_{n, 2}^{*}-\alpha y_{1, x}^{*}+(1-\alpha) y_{2, x}^{*}\right\| \\
\leq & \limsup _{n \rightarrow \infty}\left\|y_{n, 1}^{*}-y_{1, x}^{*}\right\|+\limsup _{n \rightarrow \infty}(1-\alpha)\left\|y_{n, 2}^{*}-y_{2, x}^{*}\right\| \\
\leq & \alpha \frac{\varepsilon}{16}+(1-\alpha) \frac{\varepsilon}{16}=\frac{\varepsilon}{16} .
\end{aligned}
$$

By $\alpha y_{n, 1}^{*}+(1-\alpha) y_{n, 2}^{*} \in A\left(x_{n, i}\right)$, we have $\lim \sup \operatorname{dist}\left(A\left(x_{n, i}\right), y^{*}\right) \leq \varepsilon / 16$. By the proof of $(\mathrm{d})$, we obtain that if $y^{*} \in A(x) \stackrel{n \rightarrow \infty}{=}\left[y_{1, x}^{*}, y_{2, x}^{*}\right]$, then there exists $n \in N$ such that

$$
y^{*} \in B\left(x_{n, 1}^{*}, 1-\frac{1}{4} \varepsilon\right) \cup B\left(x_{n, 2}^{*}, 1-\frac{1}{4} \varepsilon\right) \cup B\left(\frac{x_{n, 1}^{*}+x_{n, 2}^{*}}{2}, \frac{1}{2} \varepsilon\right) .
$$


Case II. Let $x \in H$ and $A(x)=\left[z_{1, x}^{*}, z_{2, x}^{*}\right]$. We define a open set

$$
U_{A(x)}=\bigcup_{x^{*} \in\left[z_{1, x}^{*}, z_{2, x}^{*}\right]} B\left(x^{*}, \frac{\varepsilon}{(32)^{2}}\right) .
$$

Since $\left\{x_{n}\right\}_{n=1}^{\infty}$ is a dense subset of $S(X)$, there exists a subsequence $\left\{y_{n}\right\}_{n=1}^{\infty}$ of $\left\{x_{n}\right\}_{n=1}^{\infty}$ such that $\left\{y_{n}\right\}_{n=1}^{\infty}$ is a dense subset of $H$. We may assume, without loss of generality, that $y_{n} \rightarrow x$ as $n \rightarrow \infty$. Then there exists natural number $N_{2}$ such that $A\left(y_{n}\right) \subset U_{A(x)}$ whenever $n>N_{2}$. Moreover, by the definition of $U_{A(x)}$, it is easy to see that

$$
\limsup _{n \rightarrow \infty} \operatorname{dist}\left(A\left(y_{n}\right), z_{1, x}^{*}\right) \leq \frac{\varepsilon}{16} \quad \text { and } \quad \limsup _{n \rightarrow \infty} \operatorname{dist}\left(A\left(y_{n}\right), z_{2, x}^{*}\right) \leq \frac{\varepsilon}{16} .
$$

Analogous to the proof of Case I, we obtain that if $y^{*} \in A(x)=\left[z_{1, x}^{*}, z_{2, x}^{*}\right]$, then there exists $n \in N$ such that

$$
y^{*} \in B\left(x_{n, 1}^{*}, 1-\frac{1}{4} \varepsilon\right) \cup B\left(x_{n, 2}^{*}, 1-\frac{1}{4} \varepsilon\right) \cup B\left(\frac{x_{n, 1}^{*}+x_{n, 2}^{*}}{2}, \frac{1}{2} \varepsilon\right) .
$$

(f) It is easy to see that for any $\delta>0$, there exists $\eta \in(0,1)$ such that $(25(1-\eta)) /(4(5 \eta-1))<\delta$. If $z^{*} \in\left\{z^{*} \in X^{*}:\left\|z^{*}-\eta x^{*}\right\|<(1-\eta) / 4\right\}$, then $(5 \eta-1) / 4 \leq\left\|z^{*}\right\| \leq(3 \eta+1) / 4$. Hence

$$
\begin{aligned}
\left\|\frac{z^{*}}{\left\|z^{*}\right\|}-x^{*}\right\| & \leq\left\|\frac{z^{*}}{\left\|z^{*}\right\|}-\frac{x^{*}}{\left\|z^{*}\right\|}\right\|+\left\|\frac{x^{*}}{\left\|z^{*}\right\|}-x^{*}\right\| \\
& \leq\left\|\frac{z^{*}}{\left\|z^{*}\right\|}-\frac{\eta x^{*}}{\left\|z^{*}\right\|}\right\|+\left\|\frac{\eta x^{*}}{\left\|z^{*}\right\|}-\frac{x^{*}}{\left\|z^{*}\right\|}\right\|+\left\|\frac{x^{*}}{\left\|z^{*}\right\|}-x^{*}\right\| \\
& =\frac{1}{\left\|z^{*}\right\|}\left\|z^{*}-\eta x^{*}\right\|+(1-\eta) \frac{1}{\left\|z^{*}\right\|}+\left(\frac{1}{\left\|z^{*}\right\|}-1\right)\left\|x^{*}\right\| \\
& \leq \frac{1-\eta}{4} \cdot \frac{4}{5 \eta-1}+(1-\eta) \frac{4}{5 \eta-1}+\left(\frac{4}{5 \eta-1}-1\right) \\
& =\frac{25(1-\eta)}{4(5 \eta-1)}<\delta .
\end{aligned}
$$

By Bishp-Phelp theorem, there exist $z_{0}^{*} \in X^{*}$ and $z_{0} \in S(X)$ such that $z_{0}^{*}\left(z_{0}\right)=$ $\left\|z_{0}^{*}\right\|$ and $z_{0}^{*} \in\left\{z^{*} \in X^{*}:\left\|z^{*}-\eta x^{*}\right\|<(1-\eta) / 4\right\}$. Let $y_{0}^{*}=z_{0}^{*} /\left\|z_{0}^{*}\right\|$. Then $y_{0}^{*}\left(z_{0}\right)=1$ and $\left\|x^{*}-y_{0}^{*}\right\|<\delta$. This implies that for any $x^{*} \in S\left(X^{*}\right)$, there exists a sequence $\left\{y_{n}^{*}\right\}_{n=1}^{\infty} \subset S\left(X^{*}\right)$ such that $y_{n}^{*} \rightarrow x^{*}$ as $n \rightarrow \infty$, where $y_{n}^{*}$ is norm attainable on $S(X)$. For any $n \in N$, we define open balls

$$
B\left(x_{n, 1}^{*}, 1-\frac{1}{8} \varepsilon\right), \quad B\left(x_{n, 2}^{*}, 1-\frac{1}{8} \varepsilon\right) \text { and } B\left(\frac{x_{n, 1}^{*}+x_{n, 2}^{*}}{2}, \varepsilon\right) .
$$

By the previous proof, we obtain that for any $x^{*} \in S\left(X^{*}\right)$, there exists $z^{*} \in S\left(X^{*}\right)$ such that $\left\|x^{*}-z^{*}\right\|<\varepsilon / 16$, where $z^{*} \in S\left(X^{*}\right)$ is norm attainable on $S(X)$. Moreover, by the previous proof, there exists $k \in N$ such that

$$
z^{*} \in B\left(x_{k, 1}^{*}, 1-\frac{1}{4} \varepsilon\right) \cup B\left(x_{k, 2}^{*}, 1-\frac{1}{4} \varepsilon\right) \cup B\left(\frac{x_{k, 1}^{*}+x_{k, 2}^{*}}{2}, \frac{1}{2} \varepsilon\right)
$$


Hence, if $z^{*} \in B\left(x_{k, 1}^{*}, 1-\varepsilon / 4\right)$, then

$$
\left\|x_{k, 1}^{*}-x^{*}\right\| \leq\left\|x_{k, 1}^{*}-z^{*}\right\|+\left\|x^{*}-z^{*}\right\|<1-\frac{\varepsilon}{4}+\frac{\varepsilon}{16}<1-\frac{\varepsilon}{8} .
$$

Similarly, we obtain that if $z^{*} \in B\left(x_{k, 2}^{*}, 1-\varepsilon / 4\right)$, then $\left\|x_{k, 2}^{*}-x^{*}\right\|<1-\varepsilon / 8$. Moreover, if $z^{*} \in B\left(\left(x_{k, 1}^{*}+x_{k, 2}^{*}\right) / 2, \varepsilon / 2\right)$, then

$$
\left\|\frac{x_{k, 1}^{*}+x_{k, 2}^{*}}{2}-x^{*}\right\| \leq\left\|\frac{x_{k, 1}^{*}+x_{k, 2}^{*}}{2}-z^{*}\right\|+\left\|x^{*}-z^{*}\right\|<\frac{\varepsilon}{2}+\frac{\varepsilon}{16}<\varepsilon .
$$

This implies that

$$
S\left(X^{*}\right) \subset \bigcup_{n=1}^{\infty}\left\{B\left(x_{n, 1}^{*}, 1-\frac{1}{8} \varepsilon\right) \cup B\left(x_{n, 2}^{*}, 1-\frac{1}{8} \varepsilon\right) \cup B\left(\frac{x_{n, 1}^{*}+x_{n, 2}^{*}}{2}, \varepsilon\right)\right\} .
$$

This completes the proof.

By Theorem 2.1, it is very natural to ask whether for any separable space $X$, if $X^{*}$ is a locally 2-uniform convex space, then there exists a sequence $\left\{x_{n}^{*}\right\}_{n=1}^{\infty}$ of strongly extreme points such that $\bigcup_{n=1}^{\infty} B\left(x_{n}^{*}, r_{n}\right)$ is a ball-covering of $X^{*}$. Unfortunately, it is not true.

Example 2.2. Let $\left(R^{2},\|\cdot\|_{1}\right)=\left\{(x, y): x, y \in R,\|(x, y)\|_{1}=|x|+|y|\right\}$ and $\left(R^{2},\|\cdot\|_{\infty}\right)=\left\{(x, y): x, y \in R,\|(x, y)\|_{\infty}=\max (|x|,|y|)\right\}$. It is easy to see that $\left(R^{2},\|\cdot\|_{1}\right)^{*}=\left(R^{2},\|\cdot\|_{\infty}\right)$ and $\left(R^{2},\|\cdot\|_{\infty}\right)$ is locally 2-uniform convex. Moreover, it is easy to see that

$$
\{(1,1),(1,-1),(-1,-1),(-1,1)\}=\operatorname{SExt}\left(B\left(\left(R^{2},\|\cdot\|_{\infty}\right)\right)\right) .
$$

Suppose that there exist $0<r_{1} \leq 1,0<r_{2} \leq 1,0<r_{3} \leq 1$ and $0<r_{4} \leq 1$ such that

$$
S\left(\left(R^{2},\|\cdot\|_{\infty}\right)\right) \subset B\left((1,1), r_{1}\right) \cup B\left((1,-1), r_{2}\right) \cup B\left((-1,-1), r_{3}\right) \cup B\left((-1,1), r_{4}\right) .
$$

It is easy to see that

$$
(0,1) \notin B\left((1,1), r_{1}\right) \cup B\left((1,-1), r_{2}\right) \cup B\left((-1,-1), r_{3}\right) \cup B\left((-1,1), r_{4}\right),
$$

a contradiction.

We next will prove that in which Banach spaces, there exists a sequence $\left\{x_{n}^{*}\right\}_{n=1}^{\infty}$ of strongly extreme points such that $\bigcup_{n=1}^{\infty} B\left(x_{n}^{*}, r_{n}\right)$ is a ball-covering of $X^{*}$. First we define a geometric constant

$$
H(X)=\sup _{x \in X}\left\{\left\|x^{*}-y^{*}\right\|: x^{*} \in A(x), y^{*} \in A(x)\right\}
$$

Proposition 2.3. Banach space $X$ is smooth if and only if $H(X)=0$.

Proof. By the definition smooth space, it is easy to see that the Proposition is true. This completes the proof. 
Theorem 2.4. Suppose that

(1) $X$ is a separable space;

(2) $X^{*}$ is a locally 2-uniform convex space;

(3) $H(X)<2$.

Then there exists a sequence $\left\{x_{n}^{*}\right\}_{n=1}^{\infty}$ of strongly extreme points such that $S\left(X^{*}\right) \subset$ $\bigcup_{n=1}^{\infty} B\left(x_{n}^{*}, r_{n}\right)$ and $\sup _{n}\left\{r_{n}\right\}<1$.

Proof. Let $2 h=H(X)<2$ and $A\left(x_{n}\right)=\left[x_{n, 1}^{*}, x_{n, 2}^{*}\right]$, where $\left\{x_{n}\right\}_{n=1}^{\infty}$ be a dense subset of $S(X)$. By Theorem 2.1, we obtain that $x_{n, 1}^{*}$ and $x_{n, 2}^{*}$ are strongly extreme points. For any $n \in N$, we define open balls

$$
B\left(x_{n, 1}^{*}, \frac{3}{4}+\frac{1}{4} h\right) \text { and } B\left(x_{n, 2}^{*}, \frac{3}{4}+\frac{1}{4} h\right) .
$$

We claim that if $\lim \sup \operatorname{dist}\left(A\left(x_{n}\right), y^{*}\right) \leq(1-h) / 16$, then there exists $n \in N$ such that

$$
y^{*} \in B\left(x_{n, 1}^{*}, \frac{3}{4}+\frac{1}{4} h\right) \cup B\left(x_{n, 2}^{*}, \frac{3}{4}+\frac{1}{4} h\right) .
$$

In fact, since $\lim \sup \operatorname{dist}\left(A\left(x_{n}\right), y^{*}\right) \leq(1-h) / 16$, there exists natural number $n_{0}$ such that $\operatorname{dist}\left(A\left(x_{n_{0}}\right), y^{*}\right) \leq(1-h) / 15$. Since $A\left(x_{n_{0}}\right)$ is compact, there exists $z^{*} \in A\left(x_{n_{0}}\right)=\left[x_{n_{0}, 1}^{*}, x_{n_{0}, 2}^{*}\right]$ such that $\operatorname{dist}\left(A\left(x_{n_{0}}\right), y^{*}\right)=\left\|z^{*}-y^{*}\right\| \leq(1-h) / 15$. Then

$$
\left\|z^{*}-x_{n_{0}, 1}^{*}\right\|<\frac{2}{3}+\frac{1}{3} h \quad \text { or } \quad\left\|z^{*}-x_{n_{0}, 2}^{*}\right\|<\frac{2}{3}+\frac{1}{3} h .
$$

Otherwise, $\left\|z^{*}-x_{n_{0}, 1}^{*}\right\| \geq 2 / 3+h / 3$ and $\left\|z^{*}-x_{n_{0}, 2}^{*}\right\| \geq 2 / 3+h / 3$. Noticing that $\left\|x_{n_{0}, 1}^{*}-x_{n_{0}, 2}^{*}\right\|=\left\|z^{*}-x_{n_{0}, 1}^{*}\right\|+\left\|z^{*}-x_{n_{0}, 2}^{*}\right\|$, we have

$$
\begin{aligned}
H(X) & \geq\left\|x_{n_{0}, 1}^{*}-x_{n_{0}, 2}^{*}\right\| \\
& =\left\|z^{*}-x_{n_{0}, 1}^{*}\right\|+\left\|z^{*}-x_{n_{0}, 2}^{*}\right\| \\
& \geq \frac{2}{3}+\frac{1}{3} h+\frac{2}{3}+\frac{1}{3} h>2 h,
\end{aligned}
$$

a contradiction. Hence we may assume that $\left\|z^{*}-x_{n_{0}, 1}^{*}\right\|<2 / 3+h / 3$. Then

$$
\left\|y^{*}-x_{n_{0}, 1}^{*}\right\| \leq\left\|y^{*}-z^{*}\right\|+\left\|z^{*}-x_{n_{0}, 1}^{*}\right\| \leq \frac{1-h}{15}+\frac{2}{3}+\frac{1}{3} h<\frac{3}{4}+\frac{1}{4} h .
$$

This implies that

$$
y^{*} \in B\left(x_{n_{0}, 1}^{*}, \frac{3}{4}+\frac{1}{4} h\right) \cup B\left(x_{n_{0}, 2}^{*}, \frac{3}{4}+\frac{1}{4} h\right) .
$$

Analogous to the proof of Theorem 2.1, we obtain that if $y^{*} \in S\left(X^{*}\right)$ is norm attainable on $S(X)$, then there exists $n \in N$ such that

$$
y^{*} \in B\left(x_{n, 1}^{*}, \frac{3}{4}+\frac{1}{4} h\right) \cup B\left(x_{n, 2}^{*}, \frac{3}{4}+\frac{1}{4} h\right) .
$$

Analogous to the proof of Theorem 2.1, we obtain that

$$
S\left(X^{*}\right) \subset \bigcup_{n=1}^{\infty} B\left(x_{n, 1}^{*}, \frac{4}{5}+\frac{1}{5} h\right) \cup B\left(x_{n, 2}^{*}, \frac{4}{5}+\frac{1}{5} h\right) .
$$

This completes the proof. 
Theorem 2.5. Suppose that

(1) $X$ is a separable space;

(2) $X$ is a locally 2-uniform convex space;

(3) $X$ is a uniformly nonsquare space.

Then there exists a sequence $\left\{x_{n}\right\}_{n=1}^{\infty}$ of strongly extreme points such that $S(X) \subset$ $\bigcup_{n=1}^{\infty} B\left(x_{n}, r_{n}\right)$ and $\sup _{n}\left\{r_{n}\right\}<1$.

Proof. Since $X$ is uniformly nonsquare, we obtain that $X$ is reflexive. By Theorem 2.4, we just need to prove that $H\left(X^{*}\right)<2$. Since $X$ is a uniformly nonsquare space, then for any $x, y \in S(X)$, there exists $\delta>0$ such that $\min \{\|x-y\|,\|x+y\|\}$ $<2-\delta$. Moreover, for any $x, y \in A\left(x^{*}\right)$, we have

$$
2 \geq\|x+y\| \geq x^{*}(x+y)=x^{*}(x)+x^{*}(y)=2 .
$$

Then

$$
H\left(X^{*}\right)=\sup _{x^{*} \in X^{*}}\left\{\|x-y\|: x \in A\left(x^{*}\right), y \in A\left(x^{*}\right)\right\} \leq 2-\delta<2 .
$$

This completes the proof.

Acknowledgement. This research is supported by by China Natural Science Fund under grant 11401084.

\section{REFERENCES}

1. S. Chen, H. Hudzik, W. Kowalewski, Y. Wang and M. Wisla, Approximative compactness and continuity of metric projector in Banach spaces and applications, Sci. China Ser A. 50 (2007), no. 2, 75-84.

2. L. Cheng, erratum to: Ball-covering property of Banach spaces, Israel J. Math. 184 (2011), no.1, 505-507.

3. L. Cheng, Ball-covering property of Banach spaces, Israel J. Math. 156 (2006), no.1, 111123.

4. L. Cheng, Q. Cheng and X. Liu, Ball-covering property of Banach spaces is not preserved under linear isomorphisms, Sci. China Ser. A. 51 (2008), no.1, 143-147.

5. L. Cheng, Q. Cheng and H. Shi, Minimal ball-covering in Banach spaces and their application, Studia Math. 192 (2009), no.1, 15-27.

6. L. Cheng, Z. Luo and X. Liu, Several remarks on ball-covering property of normed spaces, Acta Math. Sin. 26 (2010) no.9, 1667-1672.

7. L. Cheng, H. Shi and W. Zhang, Every Banach spaces with a $w^{*}$-separable dual has an $1+\varepsilon$-equivalent norm with the ball covering property, Sci. China Ser. A. 52 (2009), no.9, 1869-1874.

8. V.P. Fonf and C. Zanco, Covering spheres of Banach spaces by balls, Math. Ann. 344 (2009), no.4, 939-945.

9. R.R. Phelps, Convex Functions, Monotone Operators and Differentiability, Lecture Notes in Math., Springer-Verlag, New York, 1989.

10. S. Shang and Y. Cui, Ball-covering property in uniformly non-l ${ }_{3}^{(1)}$ Banach spaces and application, Abstr. Appl. Anal. 2013 (2013), no. 1, 1-7.

11. S. Shang, Y. Cui and Y. Fu, Smoothness and approximative compactness in Orlicz function spaces, Banach J. Math. Anal. 8 (2014), no. 1, 26-38.

12. S. Shang, Y. Cui and Y. Fu, P-convexity of Orlicz-Bochner function spaces endowed with the Orlicz norm, Nonlinear Anal. 74 (2012), no. 1, 371-379.

13. I. Singer, On the set of best approximation of an element in a normed linear space, Rev. Roumaine Math. Pures Appl. 5(1960), no.1, 383-402. 
14. F. Sullivan, A generalization of uniformly rotund Banach spaces, Canad. J. Math. 31 (1979), no.1, 628-636.

${ }^{1}$ Department of Mathematics, Northeast Forestry University, Harbin 150040 , P. R. China.

E-mail address: sqshang@163.com

2 Department of Mathematics, Harbin University of Science and Technology, Harbin 150080, P. R. China.

E-mail address: cuiya@hrbust.edu.cn 